Editorial

\title{
Introduction to the Special Issue on the Sustainable Asia Conference 2015
}

\author{
Yongrok Choi ${ }^{1, *}$, Malin Song ${ }^{2, *}$ and Seunghwan Myeong ${ }^{3, *}$ \\ 1 Department of International Trade and Regional Studies, Inha University, 100 Inha-ro, Nam-gu, \\ Incheon 402-751, Korea \\ 2 Research Center of Statistics for Management, Anhui University of Finance and Economics (AUFE), No. 962, \\ Caoshan Road, 233030, Bengbu, China \\ 3 Department of Public Administration, Inha University, Inharo 100, Nam-gu, Incheon 402-751, Korea \\ * Correspondence: yrchoi@inha.ac.kr (Y.C.); songml@mail.ustc.edu.cn (M.S.); shmyeong@inha.ac.kr (S.M.); \\ Tel.: +82-032-860-7760 (Y.C.); Fax: +82-32-876-9328 (Y.C.)
}

Academic Editor: Marc A. Rosen

Received: 7 March 2016; Accepted: 7 March 2016; Published: 12 March 2016

\begin{abstract}
Of late, Asian countries have been experiencing serious environmental disasters, such as the particulate matter (PM) smog in China, a yellow sand storm in Korea, and the Fukuyama nuclear power station shutdown in Japan. Since its inauguration in 2009, the Sustainable Asia Conference (SAC) has evolved into one of the leading international conferences for coping with these environmental challenges and presenting novel and fundamental advances in sustainable development for Asia. This editorial for SAC 2015 will highlight the contents and new methodologies put forth by selected papers, presenting diverse implications in sustainable policies and business strategies.
\end{abstract}

Keywords: Sustainable Asia Conference; innovation frontier; green growth; urbanization

\section{Background of the Special Issue}

This Special Issue consists of selected papers from the Sustainable Asia Conference (SAC) 2015, an international conference held in Lanzhou, China, on 20-21 September 2015. Since its inauguration in 2009, SAC has emerged as one of the leading international conferences for presenting novel and fundamental advances in sustainable development for Asia. The purpose of the conference is for scientists, scholars, engineers, and students from universities and research institutes around the world to present ongoing research activities and, thus, promote global research networking in the area of sustainable development. This conference provides opportunities for the delegates to come face-to-face, exchange new ideas and application experiences, establish research and business relationships, and find global partners for future collaborations. The scope of this special issue encompasses topics related to sustainable development and management at both the macro- and micro levels for Asian countries, as presented at the SAC 2015.

The majority of traditional economics and business management science is based on the argument of Adam Smith that individual competition could reveal the best solution, and this individual solution could maximize social welfare as a whole. This belief has driven rapid economic development for almost three hundred years of industrialization. This competitive optimal solution, however, has created too many undesirable byproducts of market failures, such as environmental pollution and the resultant global warming. Diverse efforts have been made to overcome this externality issue, and a new paradigm called collabonomics has evolved, involving a new paradigm in economics and business by sharing trust and values. The new paradigm is based on the synergy effect coming from the interdisciplinary, yet quite innovative, approach to handle the externality issues of undesirable outputs [1]. 
Especially, the most rapidly growing Asian countries have generated much attention worldwide due to their serious environmental situation as well as the resulting disasters. In view of these undesirable outcomes of the rapidly growing economies, the Chinese government argued that it was not ready to participate in international talks on environmental issues officially. Nonetheless, in its national policies since 2005, China has stressed more and more on the enhanced treatment of carbon dioxide emissions [2]. The approach in the SAC 2015 is quite different from those of traditional orthodox theories, where the role of the market is overemphasized and cooperation for value creation and sharing may result in worsened economic performance. Therefore, the SAC could be an important cornerstone for setting up a new platform for academic networking and discover outperforming governance in the most rapidly growing region in the world.

\section{Important Issues for a Sustainable Asia}

Sustainability science is composed of the three pillars of environment, economics, and social studies. Most of the papers in this issue are based on the harmonization of these three perspectives. Individual sustainability issues in this special edition range from the macro views of policy implications, such as urbanization and brownfield rehabilitation, to the micro views of practical suggestions, such as the social support of the home healthcare system and toy manufacturers' intermediation. Notably, the majority of the papers have focused on the social and environmentally sustainable issues in Asian countries, particularly in China, which is the largest greenhouse gas (GHG) emitter in the world. In recent times, the country's grave pollution problems have heightened the awareness of environmental issues for its government as well as the public. The Chinese government's response to this challenge should ideally be to assess the feasibility of economic growth against the constraints of resources and the environment. Compared with the SAC 2014, the papers have enlarged its sustainable content issues based on much wider applications of diverse methodologies.

Indeed, the core of the Special Issue is the sustainable governance of the policies. Considering the urgency, the Chinese and Korean governments introduced various pilot projects to promote green growth, which typically entailed more proactive policies to cope with the environmental challenges. Both countries promoted their respective pilot projects of carbon emission trading system (ETS) and diverse renewable energy development. Unfortunately, most of the policies did not perform sustainably, because of the moral hazard occurring in the participating private sector and the bureaucratic approach of the governments. In order to fill this missing link in the public private partnership (PPP) for sustainable green growth, the role of the intermediary is crucial; therefore, the intermediary propositions for green growth are proposed [1]. From the governance perspective, the PPP, as the harmonized third party, could not achieve successful governance due to internal bottlenecks, as well as external difficulties. In order to capitalize on the opportunities and strengths, and to overcome the threats and weaknesses, this paper suggests four propositions as the appropriate intermediary: facilitator proposition, network manager proposition, collaborator proposition, and service provider proposition [1].

Since coal consumption had caused the most serious environmental problems in China, it is necessary to examine the regional differences in temporal-spatial coal consumption and the factors influencing them. In an empirical test, the correlation between the level of economic development and coal consumption is shown to be positive and significant at the $1 \%$ level. This implies that the rapid economic growth across the country has dramatically increased the consumption of energy resources, particularly coal. In other words, China's economic development is happening at the expense of high energy costs, environmental pollution, and ecological imbalance. In the second stage of determining the governance factors related to coal consumption, the urbanization level is found to be negatively related to coal consumption. Thus, when the proportion of the urban population is increased by $1 \%$, coal consumption will reduce by 698,080 tons of standard coal [3]. Urbanization should be promoted with detailed fine-tuning, as it also triggers problems of social disparity and degradation of human health. Using a sequential slack-based measure (SSBM) model, another paper analyzed the spatiotemporal 
disparities of urban land use economic efficiency (ULUEE) under environmental constraints, and its influencing factors in 270 cities across China during the period 2003-2012 [4]. The empirical results show that most cities face urbanization problems, such as oversupply of labor, over-development, excessive pollutant discharge, and shortage of economic output. Especially, the unreasonable use of funds is termed as the most serious one, indicating that putting a stop to the relentless leasing of land to make up for the local government's financial deficit would be very helpful in improving the ULUEE of Chinese cities [4]. On similar lines, another paper examined a policy of attracting investments for Private Participation in Infrastructure (PPI) projects, especially in the urban areas. In terms of the environmental, social, and governance (ESG) criteria, the promotion effect of sustainable PPI investments was shown to be significant for the sustainable development of financial markets. Furthermore, it highlighted a mediation mechanism wherein the PPI investments help enlarge the size of the financial market and, thus, foster financial market liquidity as well [5]. Urbanization could reduce the consumption of coal, and the infrastructure development will foster financial markets as well. Nevertheless, one also needs to take into consideration the undesirable problems, such as the oversupply of labor and excessive pollutant discharge. Urbanization is inevitable in China, especially in the long term. However, it should mitigate the regional differences, especially in social welfare and the quality of human development. As the regional differences in human development limit the potential for sustainable development, the Chinese government urgently needs to cope with the challenges of social justice, i.e., how to achieve equal opportunities and capabilities for its huge population. Based on the convergence theory of economic growth, a paper conducted an empirical test in China for the period 1997 to 2006, involving the human development index and the three major dimensions of human development (income, health, and education) [6]. The paper concludes that the rates of return on investment in education and health decline with the increase in investment. Thus, the region with a low initial level of investment achieves a higher growth rate, and ultimately converges. This implies that urbanization helps in lowering social disparity. However, the speed for convergence is different, depending on the surrounding environment, especially with respect to government policies. When the population of the provinces is considered, the paper observes that the distribution of provincial social development in China has a tendency to converge as "twin peaks". Thus, provinces of Eastern China converge to the rich ones, while the West China converge to the poor ones, and Central China lags behind. This highlights the significance of the "rise of Central China" plan as it can play an important role in promoting an effective link between the developed Eastern China and underdeveloped Western China and harmonizing sustainable development nationwide [6].

Urbanization has presented another challenge of water pollution and shortage. With the development of urbanization, water scarcity has become more and more prominent. To promote water conservation, securing water efficiency corresponding to urban growth is an increasing challenge for policy makers. As a comprehensive indicator of water resources management, a paper utilized the water footprint to measure the total amount of freshwater used for consumption and examined the pollution issue [7]. As the variation of the water footprint in a specific region is difficult to investigate, the paper conducted a holistic assessment of the urban water footprint in Leshan City of the Sichuan Province and measured the freshwater consumption of various sectors during the period 1992-2012. The crop production sector accounts for the largest proportion of the water footprint, $41.53 \%$ on average, followed by animal products $(27.44 \%)$, indicating that the agricultural sector consumes excess freshwater recklessly and has great potential to enhance water efficiency through irrigation. Additionally, a number of policy instruments, such as pricing strategy, economic sanctions, and financial subsidies, may give rise to internalization of the external cost of water [7]. Water pollution is another severe problem in Asia. In order to handle the water pollution in a market-oriented manner, the Chinese government introduced the emissions trading system (ETS). Notably, the government controls the emission rights market. The "GDP Only" preference blocks equitable rules to address the externalities. To modify this distortion, a paper has developed a multi-objective primary distribution model that optimizes economic efficiency, environmental contribution, and fairness in the case of 
Tai lake [8]. This lake, located in the Jiangsu Province, is the third-largest freshwater lake in China with a water area of 2338 square kilometers. It experienced an explosive growth of algae in the early summer of 2007, seriously disrupting the tap water for over 10 million residents living in the six cities near the lake. This issue has raised concerns about the sustainable use and management of water resources in China. The Tai Lake problem forced the local government to improve sustainable water management. Using a non-linear programming distribution model for a water pollution, the paper confirms that the emission-rights distribution and trading in the market based on both the manufacturer's geographic location and the government's preference can help facilitate industrial structure optimization toward the local regulator's preference [8].

In order to promote sustainable development in mining of resources, such as coal and iron ore, it is necessary to rehabilitate brownfields. Brownfield, the opposite of "greenfield", generally refers to contaminated lands. These wastelands not only occupy precious land resources but also ruin the surrounding environment. Therefore, the redevelopment of wastelands can ease the land shortage crisis, create ideal conditions for transformation of cities, improve the ecological environment, improve the quality of the city, and ensure the successful implementation of a sustainable development strategy. Since the investment in a brownfield project is based on new funding, the evaluation is based on the discounted cash flow (DCF) analysis. Based on the uncertainty arising from the complicated nature of environmental recovery, the evaluation shall take into account the fuzzy real option theories as well. In the simulation model, without any time lag effect, the net present value becomes negative, which means the project is infeasible and should be surrendered. If the waiting option is considered, the investment value of this project becomes positive, which is far greater than zero, implying that this project is feasible and should be continued. Therefore, as the pollution factors in water management, making brownfield redevelopment projects full of risks and uncertainty, it is better to execute the waiting option two years later. Utilizing the fuzzy real option method, the paper highlights project management uncertainty and flexibility to evaluate the investment value accurately [9].

As mentioned earlier, the Chinese government has quite aggressively promoted policies for renewable energy, especially for the solar energy industry. Several subsidy policies have been initiated to boost the photovoltaic (PV) industry. However, to ensure sustainable governance of the policies, the subsidies for the PV industry should be considered mainly in terms of the following aspects: the provinces' and municipalities' economic condition, energy efficiency, and environmental responsibility [10]. Using 19 evaluation indicators of economic, environmental, and energy factors, along with the entropy weight method, in the 31 provinces of China, the paper carried out empirical tests to find out the optimal subsidy criteria layer. It deployed the Technique for Order of Preference by Similarity to the Ideal Solution (TOPSIS) method for sorting the assessment objects. The paper noted that the global PV industry is policy-driven and the simple Golden-Sun Project only provided two layers of capital subsidies-which are $50 \%$ of the initial investment for distributed PV systems and $70 \%$ initial investment for remote, independent PV systems. This appealing policy made companies invest large amounts of money into the PV industry, which led to a high idle rate of PV capacity and a huge waste of money and installation resources. Compared to the two-layer capital subsidy policy, the paper proposed a 31-layer policy to differentiate subsidies for regions and controlled the upper limit of capital investment into each province accurately, leading to appropriate capital flow for sustainable PV development [10]. Subsidy modes in the renewable energy industry may affect corporate financial performance as well. Thus, the relationships between the subsidy modes and financial performance of these two types of companies are investigated using a panel data model [11]. The paper begins with the classification of the subsidy modes into four categories: direct subsidy, indirect subsidy, innovative subsidy, and non-innovative subsidy. As the subsidies might not be distributed effectively because of rent-seeking behavior, the paper emphasizes that under certain circumstances, which show that the market-based mechanism has not yet been fully established, direct subsidies may have a more conspicuous influence than indirect subsidies on corporate financial performance. Innovative capacity could result in an effective increase in the profitability of enterprises. Using 26 wind and 21 solar 
energy enterprises listed on the Shanghai and Shenzhen stock exchanges for the period 2009-2014, the paper found that both indirect and non-innovative subsidies have significant effects on the financial performance of renewable energy companies. In terms of sub-industries, the subsidy effect of wind energy companies is slightly better than that of solar energy companies. The paper concludes that the subsidy mode is crucial for its effective performance and, thus, market- and performance-oriented subsidy mechanisms are definitely needed [11].

Intermediary businesses connecting local manufacturers and the international market are considered an important factor in the development of clusters [12]. Therefore, the geographical distribution and location of small and medium sales agencies (SAs) that connect manufacturers to customers, and the specialized markets (SMs) as physical exchange platforms or spaces for SAs and their clients are extremely important for the sustainable performance of the industry clusters. SMs are trading locations where a specific kind of utility commodity (sometimes mixed with a small amount of other kinds of commodities) is sold in bulk for both domestic and global markets. SAs are, generally, local independent merchants or sales departments attached to local manufacturers or even external producers in other places. They connect the local manufacturers with external clients and even foreign markets, and act as an important channel of products and information. Yiwu City in the Zhejiang Province and Linyi City in the Shandong Province are two typical examples of "commodity markets", situated in the north and south of China, respectively. Using Linyi City as the case study, Zhu et al. (2016) [13] empirically tested the factors influencing the expansion of SAs from wholesale to manufacturing and on the scale of internal production with three kinds of determinants: individual motivations of entrepreneurial innovation, local agglomeration effects of SMs, and dynamic relationships with cross-cluster cooperation. The empirical results show that individual motivations of intra-firm coordination, regional inter-firm relationships, and cross-regional inter-firm relationships have a significant and positive impact on the upgrading of local industrial clusters to sustain local competitiveness.

Sustainable governance in the health and medical care system is another key factor for a sustainable society. The medical care system in China has experienced significant changes during three decades of reforms, and thus it needs to be re-investigated for ensuring sustainable governance of these reforms. Chu et al. (2015) [14] investigated the technical efficiency of Chinese hospitals in 31 provinces during the period from 2002 to 2013 by proposing a new global generalized directional distance function (GGDDF) approach, taking into account undesirable output, i.e., mortality. In spite of the technical innovation over time, the researchers concluded that most Chinese provinces are not performing well in terms of hospitals' technical efficiency and leave a large potential to improve. In order to find out the bottlenecks or determinants for governance, the researchers took the second stage of the Tobit model, and found that the medical insurance reforms have improved the performance of Chinese hospitals, while public subsidies have decreased it. The related policy implications for Northeast Asia were derived, which included encouraging the development of private hospitals, enlarging the coverage of medical services, and pursuing customized policies for the provinces with different levels of GDP per capita and population density [14]. The problems of a shortage of medical resources and an aging population have become increasingly prominent in China. The number of elderly people aged over 60 is more than 200 million, accounting for $14.9 \%$ of the total population in China. Korea and Japan face similar challenges when it comes to aging people's healthcare. In order to cope with these medical issues, home healthcare services could provide more efficient, flexible, and convenient solutions, which can effectively alleviate the problem of a shortage of medical resources. Especially, it can reduce medical costs and improve service quality at the same time [15]. Home healthcare is defined as home-visiting medical services provided by general practitioner service teams based on online and/or phone reservation systems. Since 2003, 11 pilot community health centers have been set up in Changning, Putuo, and other districts in Shanghai. As of 2014, the system of family doctors or nurse practitioners was established in all community health centers in Shanghai, and approximately $1 / 6$ th of the residents had signed home care nursing service contracts 
with family doctors. The training level of healthcare workers and the status of medical equipment affect service quality in home healthcare. Especially, the inappropriate location of service centers for home healthcare, which is a decisive factor influencing whether medical staff are able to provide timely and convenient services for patients, is the major determinant of patient satisfaction. To examine this location governance issue, Du and Sun (2015) [15] analyzed home healthcare in Shanghai under several realistic constraints to reduce medical costs and improve medical efficiency. The researchers used the following evaluation indexes: minimum total cost of building health centers, minimum investment cost for business startup, minimum labor cost, and the minimum transportation cost. They concluded that the appropriate location of the service centers for home healthcare could decrease investment costs, avoid redundant construction, and improve the degree of patient satisfaction, contributing to the sustainable development of home healthcare [15].

With regard to the rapidly-occurring green growth, we need to consider the performance of foreign direct investment (FDI) from the economic and environmental benefits perspective as well. In 2014, the amount of FDI that China introduced reached USD \$11.9562 trillion, which is 34 times that of the amount in 1990; this inflow of FDI has certainly contributed toward the economic growth of China. Yue et al., (2016) took 104 cities in China as research objectives, and built a comprehensive index reflecting the economic and environmental effects of FDI, exploring the economic effects and environmental effects of FDI on the host country. The researchers made three contributions to the studies on China's green growth. First, by using an SBM-DDF (which stands for slack-based measure directional distance function) model, they found that FDI is helpful for China's green economic growth. Second, when the green growth efficiency is broken into economic efficiency and environmental efficiency, FDI promotes China's green economic growth through the promotion of environmental effects and economic effects. Unfortunately, FDI's promotion of environmental efficiency through clean technology transfer and environmental technology spillover may not be obvious. Third, the researchers proposed effective countermeasures to improve the effect of FDI on China's green economic growth. The government should first consider the "quality" of FDI. A high-quality FDI is good for the economy and delivers environmental benefits and, thus, it should be actively encouraged [16].

\section{Methodologies of Sustainability Science}

All papers in this special issue focus on the common paradigm of value creation based on network management. Compared with the profits, value is invisible, but it is extremely important for sustainable development policies, as well as sustainable management strategies in business. It involves a harmonized partnership, such as higher eco-friendly efficiency, better quality of social life, and the equitable economic development, as shown in the papers in this special issue. As sustainability science is based on the harmonized partnership among interrelated entities or the activities of those entities, network management is crucial for harmonizing the relationship and creating value from the partnership network [17]. Of course, the optimal solutions for harmonizing conflicting interests are not easy to evaluate and, thus, the methodological approaches could be diverse, but with more emphasis on the importance of sustainable governance. Due to the multi-disciplinary character of sustainability science, diverse approaches could and should be imported and utilized for better understanding of multivariate complexity as well as for more systematic implications and suggestions.

Since most papers in this Special Issue handle conflicting interests as well as multi-inputs/outputs for their models, traditional regression analyses may not match with these purposes. Therefore, most papers handle the multi-input/output models, such as data envelope analysis (DEA) and structural equation modeling (SEM). DEA is especially important in the field of energy and environmental economics since it handles desirable outputs as well as undesirable outputs such as wastewater and land [4], mortality rate [14], and industrial sulfur dioxide [16]. SEM or similar stepwise approaches are other popular approaches to evaluate diverse survey-related issues as they clarify the role of intermediation or stepwise relationship resulting from the complexity among variables $[3,5,11]$. As the 
sustainability issues should examine the spatial and time dynamic effects, most DEA approaches are also based on the stepwise approach [4,14].

The linear regression or linear transformation of multivariant variables is introduced as well. As coal consumption is strongly related to the distance of coal production sites, Sun et al. (2015) [3] used the center of gravity models. This is advantageous as the model can demonstrate development trajectories visually and quantitatively with the support of geographical information systems (ArcGIS) to study the spatial distribution of energy consumption and carbon emissions, and the spatial distribution of energy consumption intensity, respectively, for China's provinces and regions. Likewise, to examine the relationship between private participation in infra (PPI) investments and financial market development (FMD), Fu et al. (2016) [5] first controlled the country-fixed effect for unmeasurable country characteristics and the time-fixed effect for common shocks across countries. Then, to avoid the influence of heteroskedasticity and autocorrelation, the researchers ran a second round of estimations with robust standard errors and tested the mediator effect with the corresponding coefficients.

To determine the changing role of sales agencies (SAs) in the specialized market cluster (SMs), Zhu et al. (2016) [13] used binary logistic regression, which starts with all variables in the regression equation, and then removes the independent variables that have no significant effect on the dependent variable according to the probability value of statistics derived from the maximum likelihood estimation .

Linear programming is also used. A multi-objective mixed-integer programming model is introduced to solve the location problem for sustainable home healthcare centers [15]. Li et al. (2016) [10] introduced 19 evaluation indicators involving economic, environmental, and energy factors, allocated weight to each indicator using the entropy weight method, and sorted the 31 evaluation objects by using the TOPSIS method. To test the convergence theory with regard to the economic growth of different regions, Yang et al. (2016) [6] utilized the $\beta$-convergence method and $\sigma$-convergence method based on the fixed effects model. The former one mainly concentrates on the difference in growth rate among countries or regions, while the latter one focuses on the distribution difference in growth rate. In order to evaluate the regional water footprint in Leshan City, Zhao et al. (2015) [7] calculated all the sectors of industrial production process using the linear programming method and with the support of geographical information systems (ArcGIS) [7]. For this unique water footprint calculation, they cited 87 references, which is the largest citation in this Special Issue. A non-linear programming distribution model is introduced for water pollution emissions trading based on the local government's industrial preferences and enterprise location, along with the stepwise supplement of empirical emissions trading simulations using corporate data from the Tai Lake basin [8].

Lastly, the discounted cash flow (DCF) analysis is used to evaluate the brownfield rehabilitation projects. The fuzzy real option method is utilized for determining the uncertainty in project management [9]. The parameters in the DCF model are fixed values, such as the present value of future cash flows and investment costs. However, the present value of future cash flows and investment costs in the brownfield redevelopment project can only estimate the general scope because of pollution factors. In view of this situation, these parameters are represented by fuzzy numbers [9].

\section{Conclusions}

The research contents and methodologies examined in this Special Issue gave us greater insights and opened new frontiers to handle new challenges for sustainable governance. Most of the articles handled the multiple inputs and outputs, taking time and space into consideration. Sustainable governance should involve complicated, yet complex, procedural approaches to understand the workable mechanism and harmonize all interest groups with the cooperation network. It is not easy to clarify the causal relations on this network, but it is essential for the network manager or the agency to create and share all the challenges and values together. This is reflected in the catchphrase of the Sustainable Asia Conference (SAC): Once a friend, forever friends. 
Networking participants striving for a harmonized, sustainable performance will have to adopt a more field- and performance-oriented approach to create these invisible but precious values-this is sustainable governance [12] (p. 4115). In order to discover the sustainable governance-related factors in the rapidly evolving Asian model, sustainable issues, as well as their methodologies, should be highlighted. Especially, compared with the efficiency-oriented Western countries, the Northeast Asian countries emphasize more on the harmonized inter-relationship. This social relationship is quite crucial to create and share the values in these countries. Today, the world is shifting from the visible aspects of profits and efficiency toward the invisible values that are based on the sustainable cooperation network in the business, economy, and society as a whole. To further explore the oriental models of this sustainable cooperation network mechanism in detail, SAC 2016 shall call the papers at the end of June 2016 at Jeju Island, a paradise in the Orient.

Acknowledgments: The National Research Foundation of Korea grant funded by the Korean government (NRF-2014S1A5B1011422) supported this work.

Author Contributions: All authors made equal contributions to the work in this editorial paper.

Conflicts of Interest: The authors declare no conflict of interest.

\section{References}

1. Choi, Y. Intermediary Propositions for Green Growth with Sustainable Governance. Sustainability 2015, 7, 14785-14801. [CrossRef]

2. Yu, Y.; Choi, Y. Measuring Environmental Performance Under Regional Heterogeneity in China: A Metafrontier Efficiency Analysis. Comput. Econ. 2014. [CrossRef]

3. Sun, Y.; Li, Q.; Chen, T.; Jia, X. Dynamic Factor Analysis of Trends in Temporal-Spatial Patterns of China's Coal Consumption. Sustainability 2015, 11, 15119-15135. [CrossRef]

4. Xie, H.; Wang, W. Exploring the Spatial-Temporal Disparities of Urban Land Use Economic Efficiency in China and Its Influencing Factors under Environmental Constraints Based on a Sequential Slacks-Based Model. Sustainability 2015, 8, 10171-10190. [CrossRef]

5. Fu, T.; Chen, H.; Choi, Y. Does the Sustainable PPI Investments Promote Financial Market's Sustainable Development? Sustainability 2016, 8, 120. [CrossRef]

6. Yang, F.; Pan, S.; Yao, X. Regional Convergence and Sustainable Development in China. Sustainability 2016, 8 , 121. [CrossRef]

7. Zhao, R.; He, H.; Zhang, N. Regional Water Footprint Assessment: A Case Study of Leshan City. Sustainability 2015, 7, 16532-16547. [CrossRef]

8. Pu, Z.; Wang, H.; Bian, H.; Fu, J. Sustainable Lake Basin Water Resource Governance in China: The Case of Tai Lake. Sustainability 2015, 7, 16422-16434. [CrossRef]

9. Dai, H.; Sun, T.; Guo, W. Brownfield Redevelopment Evaluation Based on Fuzzy Real Options. Sustainability 2016, 8, 170. [CrossRef]

10. Li, L.; Chi, T.; Zhang, M.; Wang, S. Multi-Layered Capital Subsidy Policy for the PV Industry in China Considering Regional Differences. Sustainability 2016, 8, 45. [CrossRef]

11. Zhang, H.; Zheng, Y.; Zhou, D.; Zhu, P. Which Subsidy Mode Improves the Financial Performance of Renewable Energy Firms? A Panel Data Analysis of Wind and Solar Energy Companies between 2009 and 2014. Sustainability 2015, 7, 16548-16560. [CrossRef]

12. Choi, Y.; Gao, G. The Role of Intermediation in the Governance of Sustainable Chinese Web Marketing. Sustainability 2014, 6, 4102-4118. [CrossRef]

13. Zhu, H.; Huang, X.; He, Q.; Li, J.; Ren, L. Sustaining Competitiveness: Moving Towards Upstream Manufacturing in Specialized-Market-Based Clusters in the Chinese Toy Industry. Sustainability 2016, 8, 176. [CrossRef]

14. Chu, K.; Zhang, N.; Chen, Z. The Efficiency and Its Determinants for China's Medical Care System: Some Policy Implications for Northeast Asia. Sustainability 2015, 7, 14092-14111. [CrossRef]

15. Du, G.; Sun, C. Location Planning Problem of Service Centers for Sustainable Home Healthcare: Evidence from the Empirical Analysis of Shanghai. Sustainability 2015, 7, 15812-15832. [CrossRef] 
16. Yue, S.; Yang, Y.; Hu, Y. Does Foreign Direct Investment Affect Green Growth? Evidence from China's Experience. Sustainability 2016, 8, 158. [CrossRef]

17. Choi, Y.; Zhang, N. Introduction to the Special Issue on "the Sustainable Asia Conference 2014". Sustainability 2015, 7, 1595-1602. [CrossRef] 